\title{
EGU21-4579
}

https://doi.org/10.5194/egusphere-egu21-4579

EGU General Assembly 2021

(c) Author(s) 2021. This work is distributed under

the Creative Commons Attribution 4.0 License.

\section{Public acceptance of nature-based solutions (NbS): a framework for successful NbS and its application in three European case studies}

\author{
Carl C. Anderson ${ }^{1}$, Fabrice G. Renaud ${ }^{1}$, Stuart Hanscomb ${ }^{1}$, Michael Loupis ${ }^{2}$, Karen E. Munro ${ }^{3}$, \\ Alejandro Ollauri ${ }^{3}$, Depy Panga ${ }^{2}$, Eija Pouta ${ }^{4}$, Katriina Soini ${ }^{4}$, and Craig S. Thomson ${ }^{3}$ \\ ${ }^{1}$ University of Glasgow, College of Social Sciences, School of Interdisciplinary Studies, United Kingdom of Great Britain - \\ England, Scotland, Wales (c.anderson.4@research.gla.ac.uk) \\ ${ }^{2}$ Innovative Technologies Centre, Athens, Greece \\ ${ }^{3}$ The BEAM Research Centre, School of Computing, Engineering and Built Environment, Glasgow Caledonian University, \\ Glasgow, Scotland, UK \\ ${ }^{4}$ Natural Resources Institute Finland (Luke), Helsinki, Finland
}

Nature-based solutions (NbS) are increasingly recognized as sustainable approaches to address socio-environmental challenges. Disaster risk reduction (DRR) has benefited by increasingly moving away from purely 'grey' infrastructure measures towards NbS, which can better provide cultural, aesthetic, and recreational co-benefits that are highly valued among European citizens. Public acceptance is of particular importance for NbS since they often rely on collaborative implementation, management, and monitoring, as well as protection against competing land uses. Although public engagement is a common goal of NbS projects and found in the IUCN's core principles of NbS, outreach efforts are rarely based on a sufficient understanding of the (de)motivating factors tied to public perceptions. As a first step, we conducted a systematic literature review to examine how unique NbS characteristics relate to public acceptance through a comparison with grey measures. We identified influential acceptance factors related to individuals, society, and DRR measures. Based on the review, we introduce the PA-NbS framework as a starting point for the systematic consideration, design, and testing of strategies for increasing public acceptance. The PA-NbS highlights the roles of trust, competing interests, and effectiveness of $\mathrm{NbS}$, as well as public perceptions of risk, nature and place.

A lack of consideration of these factors may lead to misaligned public expectations and failed participatory initiatives, while jeopardizing the success of NbS projects. Therefore, as a second step, we conducted citizen surveys within three NbS host communities. Distinct NbS being implemented within the OPERANDUM project aim to reduce risk from (socio-)natural hazards in Scotland (landslides and coastal erosion), Finland (eutrophication and algal blooms) and Greece (river flooding). Associations of factors related to risk, nature, and place perceptions with pro-NbS attitudes and behavior were tested to determine how these may be leveraged to increase acceptance. We find that trust is a consistent factor for defining attitudes towards the NbS across the sites. Attitudes are strongly associated with respondents' commitment to nature and concern for risk, while some skepticism of NbS effectiveness leads to high public demand for relevant 
evidence. Risk perception and particularly the potential for future impacts are associated with behavioural acceptance (i.e. willingness to engage), along with responsibility for nature and connectedness to place.

Current data collection efforts to demonstrate NbS effectiveness for risk reduction are wellpositioned to increase public acceptance in Europe. However, recognizing the differences among segments of the public within each site along with distinct hazard types, proposed NbS, and historical, social, and cultural characteristics across the sites is crucial for designing strategies that increase acceptance. An overview of these dynamics leads to evidence-based recommendations for the case-study sites and for successful NbS in Europe. 